\title{
Universal seasonal snow globe surgery report
}

\author{
Martin Riegler
}

(C) Springer-Verlag GmbH Austria, part of Springer Nature 2020

Dear readers,

Welcome to this issue of European Surgery, which orchestrates a broad spectrum of general surgery related themes, topics and aims. Beauty fosters motivation. The authors, the reviewers, the Editors and the publisher are to be thanked for their support to bring these works to the attention of the readers. Reading bridges the existence. As such the readers become part of what is written, said and told. What is it, that is written, said and told? The answer is not blowing in the wind, the answer is the wind and it goes like this: what is written, said and told is the myth of man, the myth of nature, the myth of mankind and any kind and it may be taken down to the essence of all our perceptions. The essence of all our perceptions is the essence of the myth. The essence is the space time quanta orchestration of energy, which is and flows and oceans and spreads and contracts and swings and blows and repeats and dances and smiles and hopes and hates and loves and desires and kisses and kills and wishes and waits and rescues and resects and cuts and thinks and argues and motivates and takes apart and sews and dilutes and concentrates and opens and closes and forms and translates and colours and smells and bloats and burbs and rocks and reggae and blues and paints and adores and circuits and fruits and eats and delivers and plays symphonies and operas and dies and rises and falls and regurgitates and brings to the attention of the readers of the lines of this pages in the forms of the individual stream of emotions and temper and atmosphere and plays the song with the strings of the cords of

Doz. Dr. M. Riegler $(\bowtie)$

Reflux \& Health Care, Mariannengasse 10/4/9, 1090 Vienna, Austria

martin.riegler@refluxordination.at the cordial immortal stone of the tune of mood of the grandfather who has been and was and will have been a rolling stone and this makes the scene mandatory to be understood in the terms of our old good brother and sister and kids and sperms and ovaries and thyroids and livers and guts and intestines and kidneys and brains in law: let the spacetime quanta beat within, and within there it is what it is all about. Listen to the beat within, get yourself ready for the one drop dirty beat within and in between and you may understand what it is all about. Models count the phenomena and depend on our respective state of mood and atmosphere. As such physics and physiology and medicine and surgery turn the tables of science and advocate the stream of emotion into the direction of our past which is normally taken for the future. Afterworld becomes the explanation of the milky way using terms and ideas of our world down here on earth. As such gates open and close, streams flow and rise, lights come and go, rivers swallow the moon and spit it our again. Here within and in-between what happens is this: time and space cease to exist and simply are not to be taken care about within this context of intermediate storm of thunder. In contrast to that, the wide ranges of the galaxies turn out to become the playground of future generations and may expel the wish and the hope and the desire for a novel and new and actual and fascinating trip through the frontiers of our universe. Women and men get themselves together and do what has been done many times and at many occasions throughout the so called history of man. The myth goes like this:

We all came out of Africa. Otherwise remains the possibility that we also originated from South America. This would have been the parallel project. So far we lack direct scientific evidence to prove this possibility. At some point we decided to leave the home lands in Africa and spread all over the globe. We de- 
tected Europe, Asia, the Americas, the Australians, the Pacific, the moon and so forth. There we are today, we sit from continent to content, wait to be seated and fly and ride and drive and web and twitter and chat and google and burb around the PC. Fast food industries deliver the energies to support web based navigation and there we end up with the illusion to be immortal and full of possibilities handed out by the glimmering glitter of the cell phones and tablets and not by the beauty of our brains. We do not burn fires we burn our gullet, heart, head, spine and bone. We do not eat nature we navigate through the jungle of artificial food and beverages throughout the day and the night and stool smells the plastic smile of our world. In between we empty ourselves and reproduce. Reproduction and nutrition and bowel movement work and act and deliver web based and google at work. Here we are and look out for a new horizon and a new plan is to be designed and born: let us cross the milky way, let us step out into space.

The generation space ship is to be designed for future generations. Generation space ship mounted women and men will get kids and leave the earth as have our ancestors left Europe for the Americas, have left the Americas for the Pacific, have left Indonesia for Australia and so forth. The space ship generation will ride through space and it will take many hundreds of years and then those kids will discover new solar systems and planets and may also find a beautiful earth to live. Maybe they will also meet other mankind and exchange knowledge and thus spread human efforts and strategies and knowledge and myth to others out there in space and mix their ideas with those of others. Those women and men and kids (USA) and children (UK) will have their myth and we, who are living today, will be part of the myth, even you, who read those lines in this issue of European Surgery. And they will talk about a once upon a time where we lived on earth and then loaded the generation space ship and filled the ark with our ideas, hopes and desires and crossed the skies and the heavens and did so as it has been told in the ancient pyramid texts, in the ancient coffin texts of the Egyptians, as it has been told in the Gilgamesh epos of the old Sumerian culture, the Babylonians and Assyrians, the Veddas of the Indus valley culture and so on. We have not yet found the scriptures of the Olmecs, the Mississippi culture, the ancient Chinese legacies and so on. Cheap copies of the old stuff have been used to fill the torah, the bible, and so forth. And then these far out future generations will remember the times when women and men sat around a fire place in Africa, once upon a time when it all had begun, and when those ancestors started their myth telling by bringing the stars down to earth, before they themselves became the stars, which will be visited by those in the far future generation space ships thereon. Dear reader: mirror heavens during life and after death, be one of the fundamental principles of life which translate into the understanding of space time quanta and the curve of our existence. And here we understand what women and men and kids perceived when they have been allowed to sit around the fire place and to watch the fire and listen to the myths told by the old members of the group: the myth of man is all about you and about hope, desire and love. And, most important it is all about cosiness, protection and security. "Once upon a time you could have been loved!”

Festivities around the globe aim to remember and recall these fundamental tunes of emotion, states of atmosphere including security, love, attention, respect and cosiness. Stories and themes have been invented and orchestrated into the form of the myth of mankind to deliver cosiness and love and protection to the people, at least for short moments within a stressful year. And here comes into play the idea to bring back childhood emotions, when the great surgeons of today have been kids and awaited the fascinating themes and topics of the winter time and Christmas time all over the globe. And the myth of mankind invented a story which dresses the world into a suit of love, peace and protection and caresses women and men and kids with cosiness. And this theme of emotion is wonderful and helps to bridge the hard and brutal and stressful and high speed reality of today. As thus we dig into the ocean of emotion

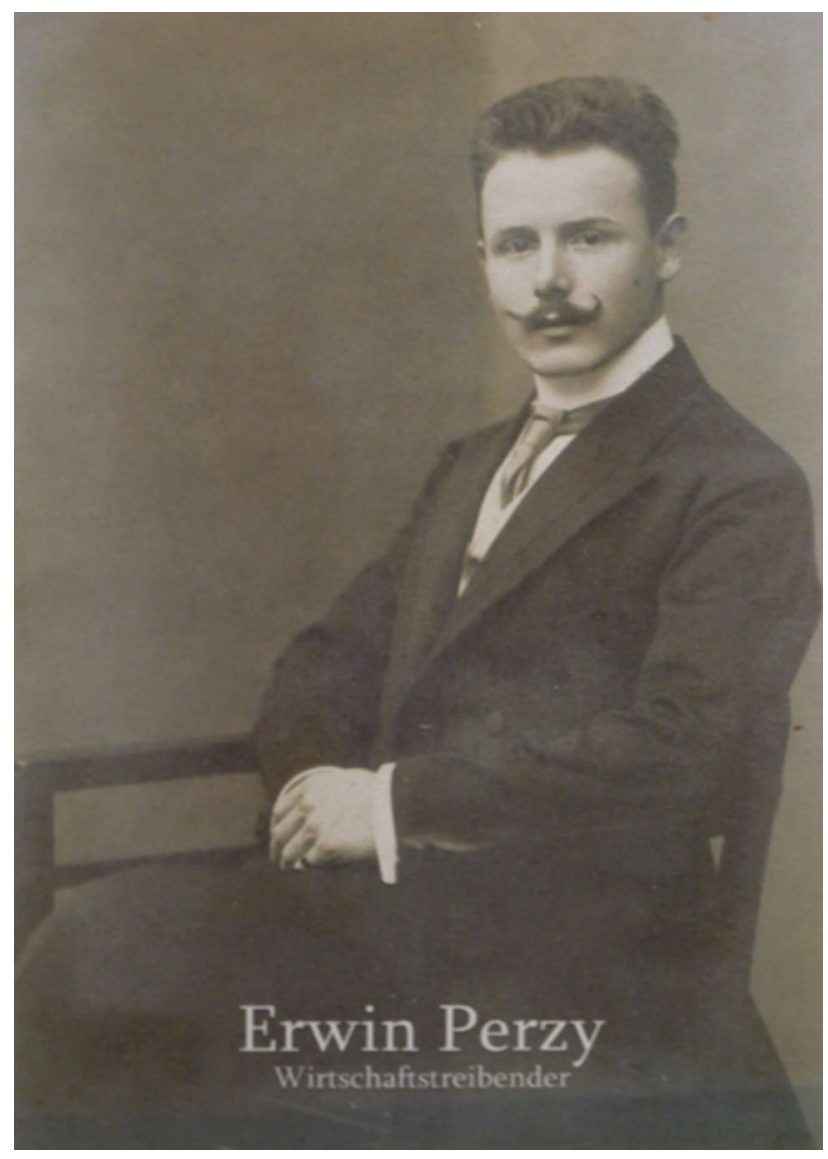

Fig. 1 Image of Erwin Perzy I, the inventor of the Vienna snow globe. Image due to the courtesy of Erwin Perzy III 


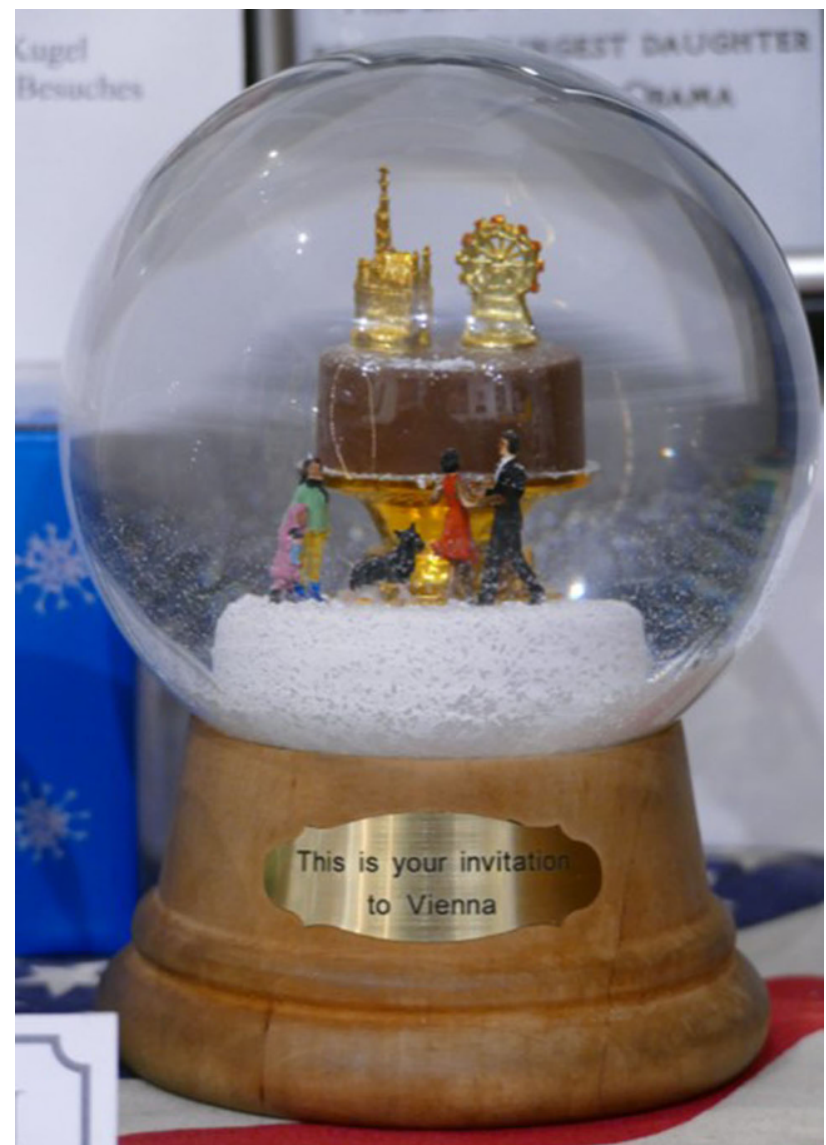

Fig. 2 Snow globe designed for US president Obama and his wife staging typical Viennese semiotics including the Sacher chocolate cake, St Stephans Cathedral and the Vienna ferris wheel. Image due to the courtesy of Erwin Perzy III

and see what the myth is going to tell if physics and medicine come into play.

Around 1900 the Viennese instrument maker Erwin Perzy I did not only produce scissors and forceps and scalpels and knifes for the surgeons of the famous Vienna Medical School at the old Vienna General Hospital (Fig. 1; [1]). He also searched for a better and new method to improve the quality of OR lights. During his search he discovered a possibility to translate cosiness into a globe, to transform love, peace and happiness into a physical form, he invented the Vienna snow globe. As such, the development of surgical instruments is directly connected to the invention of the famous Vienna snow globe. Today the third generation of Perzy, Erwin Perzy III is at work and has given the responsibilities to the fourth generation, Sabine Perzy II. Family business works and due to the broad spectrum of ideas the flower grows and continues to grow (Figs. 1, 2, 3, 4 and 5). There is still enough space for any time.

Conceptually the snow globe recalls the remembrance of everybody's childhood Christmas time experiences, which are basically tuning out the same: the wish for love, peace and attention, the security of cosiness within the context of the family, and thus

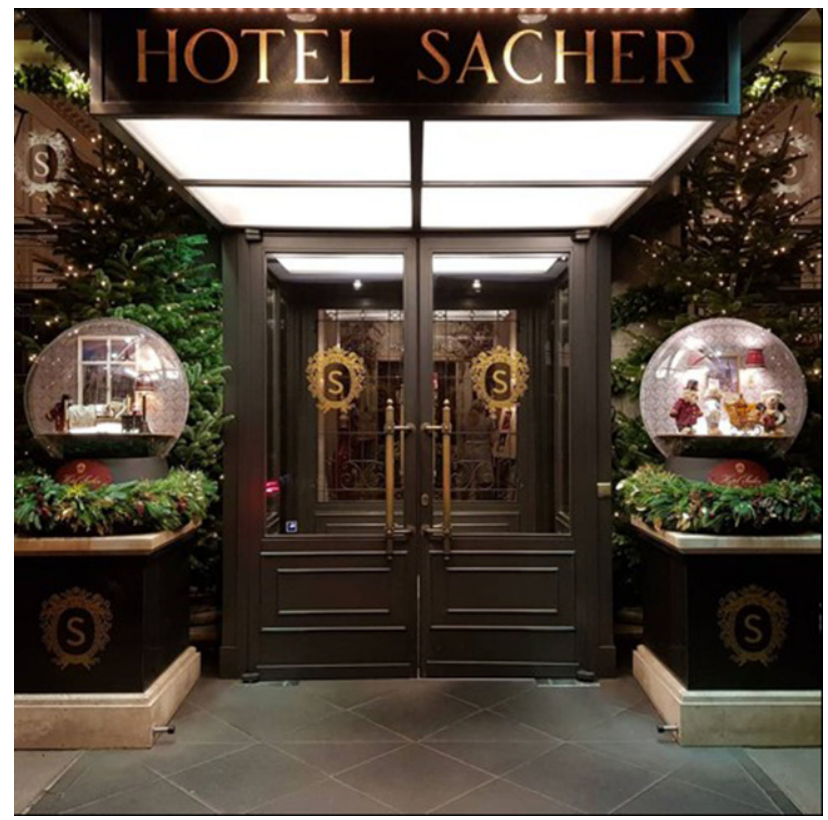

Fig. 3 Large snow globes lining the entrance of the famous Viennese Hotel Sacher. The image mirrors the idea of the author that the semiotics of the snow globe fosters positive atmospheres and emotions including cosiness, as outlined in the text. Image due to the courtesy of Erwin Perzy III

the snow globe tells the essence of the myth of man (Figs. 1, 2, 3, 4 and 5). As such man made its way out of Africa and all over the globe and through space to the moon and will sooner or later ride out into the galaxies of our universe. Wherever man is going to ride and hide, prosper and foster, harry and wait, man will look out for moments of love, peace, attention, respect and cosiness. The snow globe represents a unique and beautiful translator for such moments of relaxed emotions and atmospheres (Figs. 2, 3, 4 and 5). Therefore, the snow globe sends the message within the frame of the stage it refills: be you and be happy, at least for a few moments within this web based and hate and devil driven google over estimated world. The snow globe offers the possibility to step out of hateful strife and live according to the nature of man, as suggested by Hesiod with his Theogony [2], as suggested by Heraclitus and Parmenides, as depicted by Hieronymus Bosch, Michelangelo and Dürer, and many more. And here music comes into play. Sing the song and listen to every tune and every nuance of the spectrum of purity. This river never runs dry.

The snow globe sets the stage for people, things and emotions and orchestrates them within the context of a highly positive atmosphere and tune and temper of mood: cosiness helps to forget and fosters moments of security and happiness. Put your dreams into reality: unity and peace are possible (Figs. 2, 3, 4 and 5). This is what surgeons need today. This is what men, women and kids need to face today: love, respect and attention. May these seasonal greetings foster the theme. 


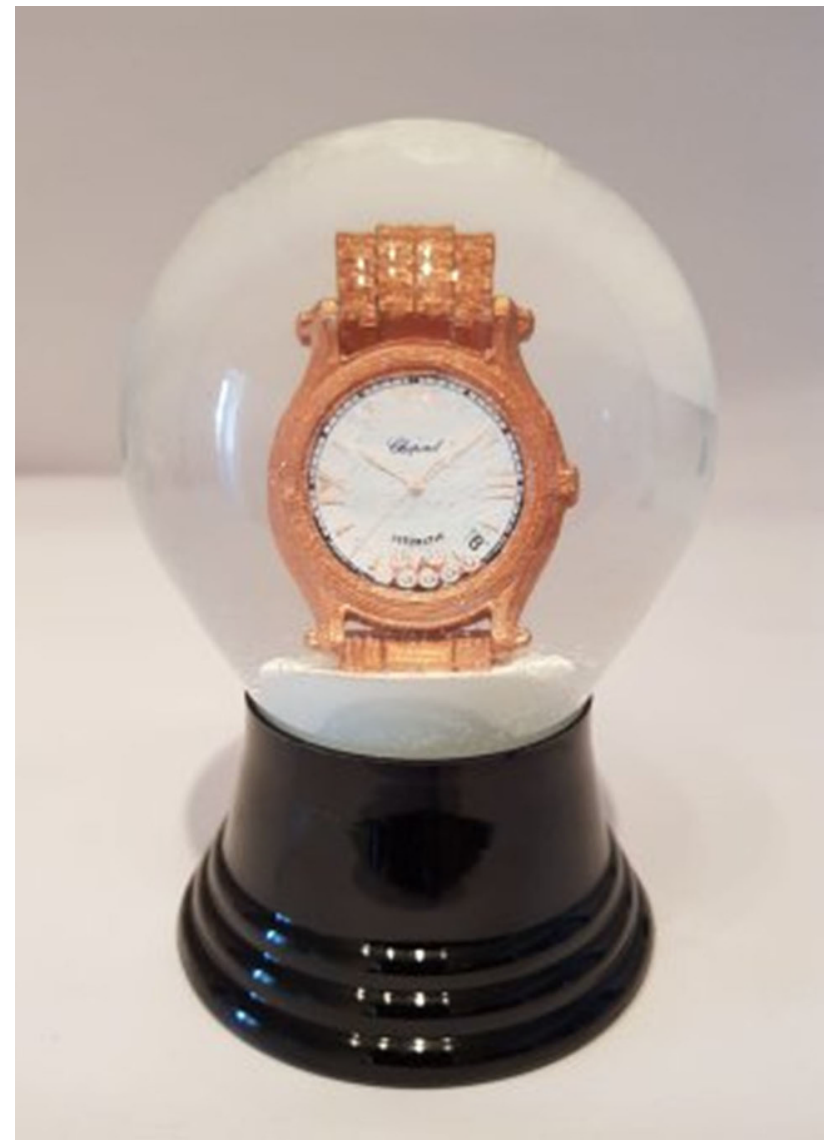

Fig. 4 Snow globe staging Chopard swatch reflecting the idea of the author that all perceptions are basically representations of space time quanta manifestations, as outlined in the text. Image due to the courtesy of Erwin Perzy III

Taken together, the snow globe is more than an important invention coming from the cradle of music, it is more than a beautiful present originated in Vienna, the Vienna snow globe contains the legacy of our ancestors and translates into our perceptions what does not have to get lost: love, humility, respect and attention. Let the dream of unity, love, peace and happiness come true, at least for some moments of major significance $(p<0.001)$.

Before we fill the generation space ships and before we cross and travel around the universe we have to define how to establish life, food, medicine, and surgery within this ark. Of course snow globes will be on board. As long as the idea seems to await realisation we are allowed to cross the ocean of our emotions and the snow globe may help us to positively do so. Close your hands and feel your globe and how the snow alters the fall of your heart beat. Sensation counts, not the matter.

Get yourself together and have a great time with your families, friends, neighbours and colleagues to celebrate the seasonal atmosphere and may snow globe enrich your thoughts, minds and colours of mood, temper and strings of decision. Be you and stay tuned all over the globe, may space time

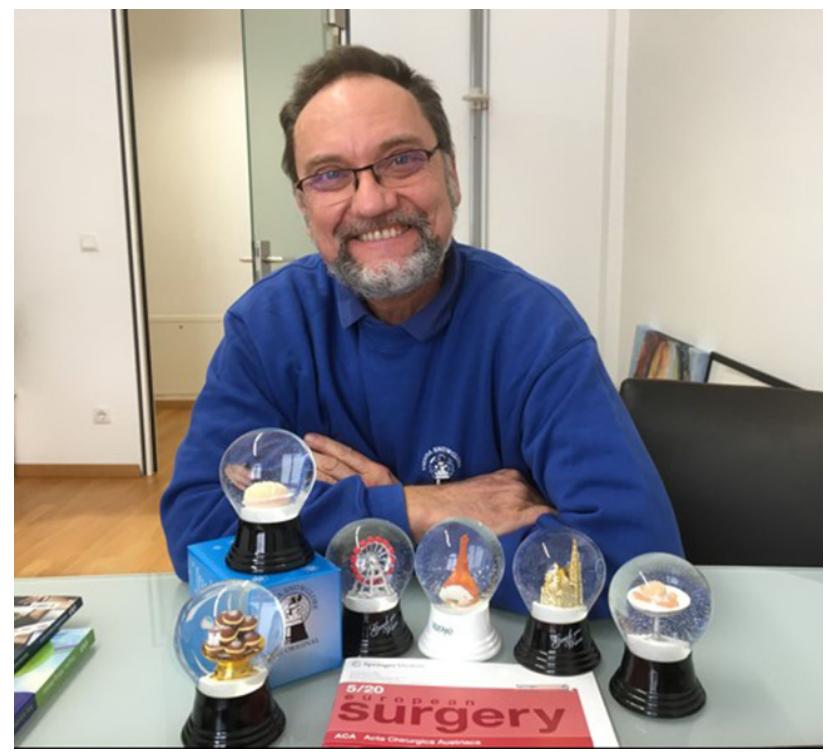

Fig. 5 Erwin Perzy III behind a set of snow globes staging different foods (sweeties, cakes, ham) and architecture (Vienna St Stephans Cathedral, Vienna ferris wheel), as outlined in the text. Image obtained by the author in the Old Vienna Poliklinik

melt away all bad vibrations and foster success in 2021.

Sincerely yours, Martin Riegler.

Acknowledgements The author thanks his patients to learn about the beat within and in between the perceptions made during the conduct of disease assessment, diagnosis and therapy and the manifestation of the world within the context of the continuous appearing tune of mood and atmosphere. The author thanks his wife, parents, sister and family and friends for supporting the journey towards the legacy of human history entitled the myth of mankind. Finally this is to thank all contributors supporting the project of European Surgery which is to approximate truth as much as possible. The author thanks all authors, reviewers, editors, Springer and the readers of European Surgery. With their activities this flower would not grow. May the snow globe story motivate a positive year 2021.

Conflict of interest M. Riegler declares that he has no competing interests.

\section{References}

1. OriginalVienneseSnowGlobeEU.Schumanngasse 87;1170 Vienna https://viennasnowglobe.at/index.php/vienna_ en/contact/. Accessed 23 Oct 2020

2. Riegler M, Schoppmann SF. Multidisciplinary management: alternative perspectives for themanagement of gastroesophageal reflux disease (GERD) and Barrett's esophagus (BE). In: Schoppmann SF, Riegler M, editors. Multidisciplinary management of gastroesophageal reflux disease. Cham: Springer;2021. p. 187-203.

Publisher's Note Springer Nature remains neutral with regard to jurisdictional claims in published maps and institutional affiliations. 